\title{
VOLUMETRIC AND HISTOLOGICAL EVALUATION OF OSTEON II COLLAGEN WITH HYALURONIC ACID VERSUS STICKY BONE GRAFT IN THREE DIMENSIONAL SOCKET PRESERVATION
}

\author{
Abdel Aziz Baiomy Abdullah Baiomy*, Hossam El-Din Mohamed Ali*, \\ Mohammed Mahgob Mohammed Al-Ashmawy ${ }^{* *}$ and Ibraheem Mahmoud Mwafey****
}

\begin{abstract}
Aim: To compare socket bone preservation using Osteon II Collagen mixed with Hyaluronic Acid (Hy A) versus autologous concentrated growth factors enriched bone graft matrix (sticky bone) assessed by 3D cone beam computed tomography and histological evaluation .
\end{abstract}

Patients and methods:30 patients were treatment planned for extraction of mandibular first molar teeth, leaving 30 sockets for the study. Sockets were divided randomly into two equal groups. Sockets were grafted as follows: Group (I) sockets were grafted by Osteon II Collagen mixed with Hy A, Group (II) sockets were grafted by sticky bone graft. A cone beam computed tomography (CBCT) radiographs at one day, 3 and 6 months were postoperatively done to assess bone density and tooth socket dimensions. Microscopic evaluation was performed at 6 months before implant insertion. All readings were recorded and analyzed statistically.

Results: There is a high statistically significant difference between study groups as regards the mean values of bone density, bone height, and percentage of volume change. In another the side ,other parameters showed insignificant differences between the study groups. Histological study referred to more maturation of bone in group I than group II.

Conclusion: The results clearly concluded that both Osteon II Collagen mixed with HyA and sticky bone are successful in achieving clinical and 3D volumetric socket bone preservation with superiority for Osteon II Collagen mixed with Hy A.

KEYWORDS: socket preservation, Osteon II Collagen, sticky bone „Hyaluronic Acid (Hy A), cone beam computed tomography (CBCT).

* Ass. Professor of Oral and Maxillofacial Surgery, Faculty of Dental Medicine (Assiut) - Al-Azhar University

** Lecturer of Oral and Maxillofacial Surgery Faculty of Dental Medicine (Assiut) Al-Azhar University

*** Lecturer in Oral Medicine, Periodontology, Oral Diagnosis and Dental Radiology Faculty of Dental Medicine (Assuit) Al-Azhar University. 


\section{INTRODUCTION}

One of the most common challenges in a dental field is bone resorption after tooth extraction. Postextraction alveolar ridge resorption is a common phenomenon that impairs placement of dental implant with respect to position and angulations and may cause aesthetic problems in prosthetic dentistry ${ }^{(1-3)}$.

In an attempt to attenuate the resorption events that follow tooth loss and to minimize the need for ancillary ridge augmentation procedures prior to delivery of dental implant socket preservation technique has been proposed. Where, socket preservation helps to maintain the alveolar ridge architecture and significantly reduces the external changes ${ }^{(4-7)}$.

Various regenerative biomaterials used for socket preservation including auto-grafts, allografts, xenograft, alloplasts and platelet rich growth factors alone or in combination with guided bone regeneration membrane ${ }^{(4,7-9)}$.

Among various bone graft materials which used in socket preservation, calcium phosphate bone substitutes have been widely used due to their chemical similarity to human bone. Osteon II is one of alloplastic materials composed of hydroxyapatite $70 \%$ and betatricalcium phosphate $30 \%$ which are most close to major mineral components of human bone. It is osteoconductive material that acts as bone growth scaffold. It has interconnected porosity structure which is similar to that of human cancellous bone ${ }^{(10,11)}$.Collagen can be added to osteon II to allow easy manipulation and shaping during grafting procedure and to increase the osteoconductivity of Osteon II such as presenting in Osteon II collagen which composed of synthetic bone graft and bovine type I collagen ${ }^{(12)}$.

Recently, to accelerate healing of bone graft in the bony defect, numerous techniques utilizing platelet and fibrinogen concentrations have been described in the literature ${ }^{(13,15)}$. Accordingly, several studies $^{(16,17)}$ used a newly developed autologous concentrated growth factors (CGF) enriched bone graft matrix (sticky bone)combine with guided tissue regeneration or no in socket preservation. Where, sticky bone has numerous advantages such as 1) it is moldable, so well adapted over various shape of bony defect; 2) Fibrin network entraps platelets and leukocytes to release growth factors, so bone regeneration and soft tissue is accelerated; 3) No biochemical additives are needed to make sticky bone; 4) Fibrin interconnection minimizes soft tissue ingrowth into the sticky bone $\operatorname{graft}^{(17)}$.

In the same context, several researchers ${ }^{(18,19)}$ reported that Hyaluronic acid (HyA) capable to accelerate the onset of new bone formation when it is added to alloplastic bone graft for bone augmentation of alveolar defects. Where, HyA increases osteoblastic bone formation through increased mesenchymal cell differentiation and migration. Accordingly, adding of HyA to Osteon II collagen could be a valuable in promoting bone healing in socket preservation technique.

Therefore, the present study was a trial to assess clinical and 3D volumetric efficacy of a mixture of HyA with Osteon II collagen versus sticky bone(a mixture of autologous concentrated growth factors with Osteon II collagen) in socket bone preservation.

\section{PATIENTS AND METHODS}

This study was designed as a randomized controlled clinical and radiographic study carried out on total 30 patients of both sexes (13 females and 17 males ranged in age from 21-43 years). All patients were selected from those attending the outpatient clinic of the Department of Oral and Maxillofacial Surgery, Faculty of Dental Medicine, Boys, Assiut, Al-Azhar University. They were planned for extraction of hopeless mandibular first molar tooth followed by delayed implant placement. Informed consent was obtained from all patients before any study procedures were performed. 


\section{Selection criteria:}

- Inclusion criteria: Patient with decayed lower first molar with adequate bone at least 3-4 mm beyond the apex of the tooth

- Exclusion criteria: Soft tissue recession at the extraction site, perforation and/or loss of labial bony plate following tooth removal, un-cooperative patients, patient with medical history that would complicate the outcome of the study, and smoking patients. Also, patients with history of radiotherapy or chemotherapy in the head, and neck region and use of bisphosphonate therapy.

\section{Patient grouping:}

Patients classified randomly into the following two equal groups using online software (https:// www. randomizer.org):

- Group I: included 15 patients with 15 fresh extraction sockets of mandibular first molar grafted by mixture of osteon II collagen (GENOSS, Dentium. Co. Ltd, Suwon, South Korea) with Hy A(Hyadent, BioScience $\mathrm{GmbH}$-Germany) covered by collagen membrane

- Group II: included 15 patients with 15 fresh extraction sockets of mandibular first molar grafted by sticky bone graft and covered by collagen membrane (GENOSS, Dentium. Co. Ltd, Suwon, South Korea).

\section{Preoperative phase:}

Patients' data were collected and, medical and dental histories were taken. Also, all patients underwent pre-operative clinical examination and periapical radiographs to exclude any pathosis and evaluate the dimensions of the socket.

\section{Preparation of sticky bone graft ${ }^{(17,20)}$ :}

- 20CC of patient's venous blood was taken from patient's forearm vein.
- The blood in the test tube was centrifuged at 2400-2700rpm for two minutes.

- The test tube showed two different layers. The upper layer was autologous fibrin glue (AFG) layer and red blood cells were collected in bottom layer which was discarded.

- The upper AFG was obtained with syringe and mixed with particulate bone powder osteon II collagen (GENOSS, Dentium. Co. Ltd, Suwon, South Korea) and allowed for five-ten minutes for polymerization in order to produce sticky bone which is yellow colored.

\section{Operative phase:}

- After local anesthesia had been administered, sulcular incisions were given around the premolars with a sharp instrument such as a No.15 scalpel.

- Periotome was used to dissect the attached fibers. The blade had to be angled at 20 degrees to ensure that the tip of the periotome was within the crest of the alveolar bone.

- The instrument was inserted first in the gingival sulcus, and then in the periodontal ligament space. The periotome was moved repeatedly in a mesio-distal direction, along the circumference of the root.

- Finally, the extraction of the tooth was performed with forceps without distorting or damaging the alveolar bone.

- After tooth extraction, any soft and hard tissues debris was curetted, and then all patients underwent $\mathrm{CBCT}$ imaging before tooth socket grafting.

- In group I ,a mixture of osteon II collagen with HyA was grafted into the socket up to $2 \mathrm{~mm}$ apical to the soft tissue margin (Fig. 1).

- In group II, sticky bone graft was grafted into the socket up to $2 \mathrm{~mm}$ apical to the soft tissue margin (Fig. 2). 


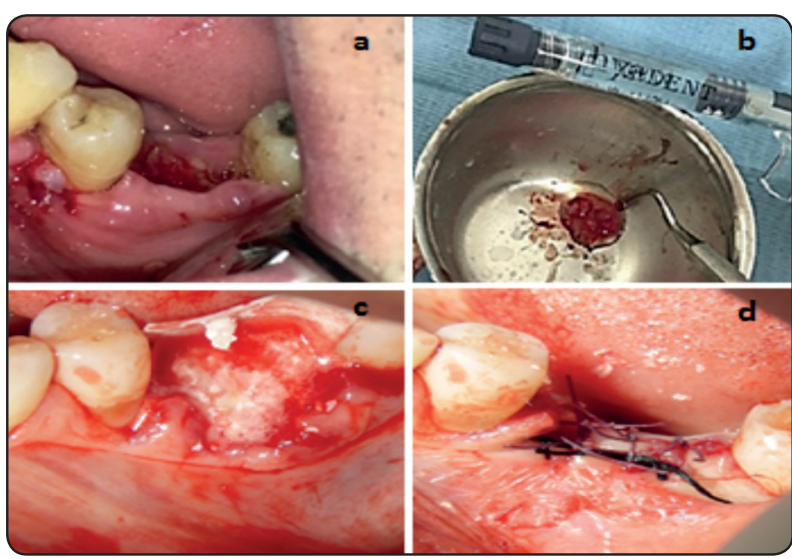

Fig. (1) (a) Lower first molar socket after a traumatic extraction (group I) (b) Preparing mixture osteon II collagen with HyA (c) Mixture osteon II collagen with HyA was placed in tooth socket and collagen membrane in position to cover bone graft (d) wound closure.
- After socket grafting, surgical site was covered by a collagen membrane in both groups then surgical site was sutured by interrupted suturing.

\section{Postoperative phase :}

After surgical procedures, AmoxicillinClavulanic acid (Augmentin, GSK, UK) antibiotic (1 gram/12 hours) was prescribed for 7 days. Diclophenac potassium (Cataflam, Novartis, Switzerland) (50 mg/8 hours) was prescribed for 3 days. Chlorhexidine mouthwash (Listermix Plus, Sigma, Egypt) (every 8 hours) was prescribed to be used starting the day following the surgery for 15 days. Also, standard post-surgical instructions were given to the patients. The patients were instructed to avoid cutting food at the operated sites for 2 weeks and preserve on a good oral hygiene.

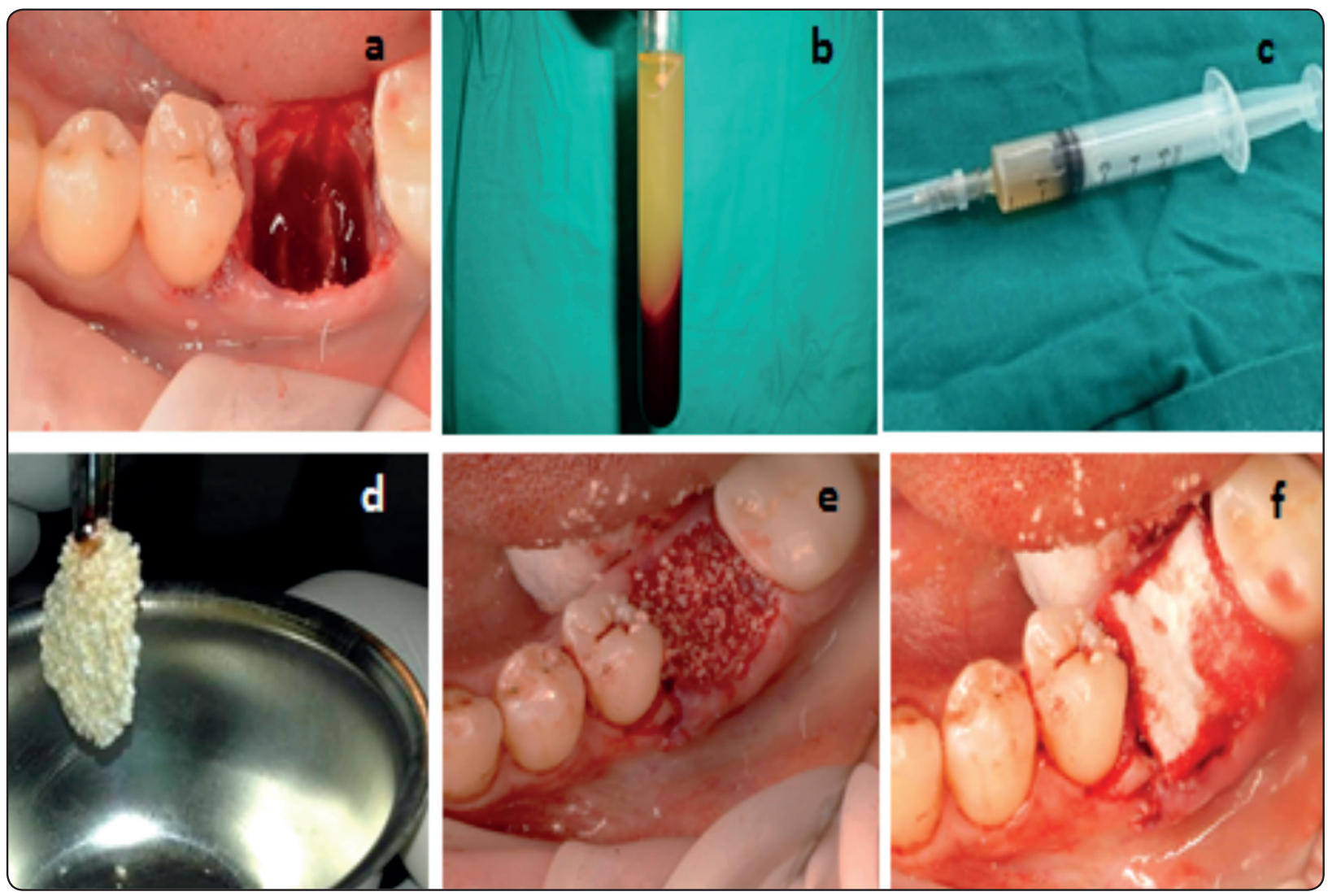

Fig. (2) (a) Lower first molar socket after a traumatic extraction (group II) (b) AFG at upper part of tube after centrifuging (c) AFG aspirated by syringe (d) Prepared sticky bone (e) AFG was placed in tooth socket (f) collagen membrane in position to cover bone graft. 


\section{Follow up phase :}

\section{Clinical evaluation:}

\section{Radiographic evaluation:}

Bone density and socket dimensions were evaluated after the treatment by using a cone beam computed tomography (CBCT) radiograph (Kodak 9500 cone beam 3D system). At 24 h, 3, and 6 months postoperative intervals, to assess bone density and vertical, horizontal and bucco-lingual dimensions as following :

- Bone Density Assessment: By using beam CBCT software, the means values of bone density were recorded, and the change in the density of the graft was calculated in Hounsfield units (HU).

- Socket dimensions: By using beam CBCT software, the socket dimensions were calculated in millimeters $(\mathrm{mm})$. Vertical line was set parallel to the tooth axis of the tooth before extraction. It was measured from the most apical point of the alveolar socket to the height of the crest. The horizontal line (mesio-distal) was set perpendicular to the vertical line to measure distance of edentulous area between two teeth. The bucco-lingual dimensions were measures from the most height point at a buccal plate to the most height point at a lingual plate. The mean values of the three dimensions were recorded. Also, volume of grafted socked was calculated in $\mathrm{mm} 3$ to present percent of volume change at end of study (Fig.3).

\section{Histological evaluation:}

Bone biopsies were harvested using a trephine bur at the site that will prepare for implant placement in the future. The trephine burs including the bone biopsies were fixed in 4\% formalin for 5-7 days, rinsed in water and dehydrated in serial steps of ethanol (70, 80, 90, and 100\%), the specimens were then stained by hematoxylin- eosin for light microscopic evaluation.
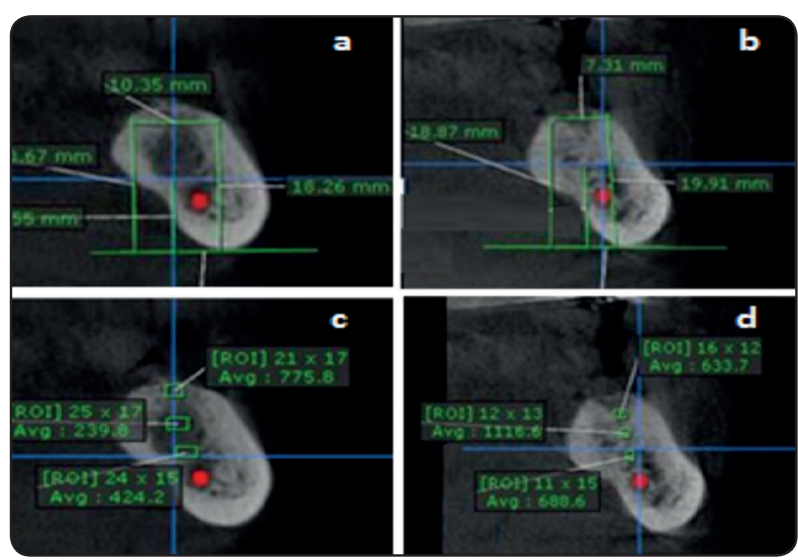

Fig. (3) Coronal view CBCT of group I \& II at 6 month interval showing, measurements of vertical bone height (Buccal, lingual and bottom) and horizontal dimensions of the socket in (a) group I \& (b) group II. Coronal view CBCT of group I \& II at 6 month interval showing measurements of bone density in (c) group I \& (d) group II.

\section{Statistical analysis:}

Data was represented as a mean and standard deviation. Paired Student's t-test was used when comparing between the two groups. Unpaired t-test was used to compare numeric variables within both groups during intervals of the study. Data were analyzed using the statistical package for social sciences, version 20.0 (SPSS Inc., Chicago, Illinois, USA). Result was considered statistically significant if the p-value was less than 0.05 .

\section{RESULTS}

\section{Clinical evaluation}

All the patients tolerated the procedure well with slight to mild pain sensation at surgical site for one to three days duration after surgical procedures. There was no significant difference between both groups at all intervals of the study. Where, all patients showed excellent soft tissue healing, and fully keratinized mucosa without any signs of inflammation, infection or dehiscence. 


\section{Radiographic Parameters}

Paired t-test statistical analysis for means values of $\mathrm{CBCT}$ data presented that no statistically significant difference between both groups regarding mesio distal and bucco-lingual measurements at all intervals. On the other side ,measurements of bone height and volume of grafted socket showed statistically significant difference between both groups at 3 month interval $(\mathrm{p}<0.05)$ and highly statistically significant difference at 6 month intervals ( $\mathrm{P}<0.01)$. Where, measurements of bone height and volume of grafted socket decreased in group II more than group I. Also, bone density scores showed higher values in group I than group II with highly statistically significant difference at 3,6 month intervals. Although, both group did not show any statistically significant difference at baseline (table .1).
Unpaired t-test statisticalanalysis for each group at different intervals representedgradual decrease in bone height, and volume of grafted socket measurements with gradual elevation in bone density readings during observation period of the study. Where, group I showed low statistically significant difference in comparing the baseline with 6 month regarding to bone height measurements. The difference was highly statistically significant in comparing the base line with 6 month regarding to bone volume and with 3 month and 6 month regarding to bone density. Group II presented highly statistically significant difference in comparing the base line with 3 month and 6 month ( table 2).

High statistically significant differences $(\mathrm{P}<0.01)$ between both groups were soon at 6 months regarding to the amount of change in bone density and bone height measurements, and

TABLE (1) Comparison between mean and standard deviation of both groups at different intervals.

\begin{tabular}{|c|c|c|c|c|c|}
\hline Parameters & Postoperative Intervals & $\begin{array}{c}\text { Group I } \\
\text { Mean } \pm \text { SD }\end{array}$ & $\begin{array}{c}\text { Group II } \\
\text { Mean } \pm \text { SD }\end{array}$ & $\mathrm{t}$-value & P-value \\
\hline \multirow{3}{*}{ Bone Height } & $24 \mathrm{H}$ & $8.93 \pm 3.12$ & $9.02 \pm 2.42$ & 1.047 & 0.309 \\
\hline & $3 \mathrm{M}$ & $8.50 \pm 2.73$ & $7.31 \pm 2.61$ & 2.161 & $0.049 *$ \\
\hline & $6 \mathrm{M}$ & $8.18 \pm 2.65$ & $7.06 \pm 1.58$ & 6.054 & $0.000 * *$ \\
\hline \multirow{3}{*}{ Mesio-distal } & $24 \mathrm{H}$ & $8.01 \pm 0.62$ & $7.93 \pm 0.95$ & 0.15 & 0.875 \\
\hline & $3 \mathrm{M}$ & $7.92 \pm 0.57$ & $7.46 \pm 0.69$ & 0.53 & 0.596 \\
\hline & $6 \mathrm{M}$ & $7.79 \pm 0.46$ & $7.40 \pm 0.67$ & 1.14 & 0.263 \\
\hline \multirow{3}{*}{ Bucco-lingual } & $24 \mathrm{H}$ & $6.95 \pm 0.74$ & $7.04 \pm 0.93$ & 0.35 & 0.724 \\
\hline & $3 \mathrm{M}$ & $6.83 \pm 1.06$ & $6.45 \pm 0.92$ & 0.30 & 0.765 \\
\hline & $6 \mathrm{M}$ & $6.31 \pm 0.94$ & $6.17 \pm 046$ & 0.07 & 0.943 \\
\hline \multirow{3}{*}{ Volume $\left(\mathrm{mm}^{3}\right)$} & $24 \mathrm{H}$ & $497.12 \pm 1.43$ & $503.56 \pm 2.13$ & 1.47 & 0.155 \\
\hline & $3 \mathrm{M}$ & $459.79 \pm 1.65$ & $351.73 \pm 165$ & 2.30 & $0.031 *$ \\
\hline & $6 \mathrm{M}$ & $402.087 \pm 1.14$ & $322.34 \pm 0.97$ & 3.61 & $0.004 * *$ \\
\hline \multirow{3}{*}{$\begin{array}{c}\text { Bone Density } \\
\text { (HU) }\end{array}$} & $24 \mathrm{H}$ & $512.50 \pm 70.54$ & $521.80 \pm 63.28$ & 2.2 & 0.053 \\
\hline & $3 \mathrm{M}$ & $632.90 \pm 121.39$ & $593.40 \pm 85.63$ & 9.2 & $0.000 * *$ \\
\hline & $6 \mathrm{M}$ & $774.60 \pm 138.36$ & $671.31 \pm 76.05$ & 10.4 & $0.000 * *$ \\
\hline
\end{tabular}


TABLE (2) Comparison between measurements of each parameter at different intervals in the same group.

\begin{tabular}{|c|c|c|c|c|c|c|c|c|}
\hline & \multicolumn{4}{|c|}{ Group 1 } & \multicolumn{4}{c|}{ Group 2 } \\
\cline { 2 - 10 } & \multicolumn{2}{|c|}{$3 \mathrm{M}$ VS 24H } & \multicolumn{2}{|c|}{$6 \mathrm{M}$ VS 24H } & \multicolumn{2}{c|}{ 3M VS 24H } & \multicolumn{2}{c|}{$6 \mathrm{M}$ VS 24H } \\
\cline { 2 - 11 } & $\mathrm{t}$-value & P-value & t-value & P-value & t-value & P-value & t-value & P-value \\
\hline Bone height & 1.056 & 0.318 & 2.35 & $0.041^{*}$ & 11.53 & $0.000^{* *}$ & 14.08 & $0.000^{* *}$ \\
\hline Mesio-distal & 0.965 & 0.360 & 0.761 & 0.466 & 2.177 & 0.057 & 1.328 & 0.217 \\
\hline Bucco-lingual & 1.527 & 0.161 & 1.444 & 0.183 & 1.40 & 0.178 & 2.35 & $0.032^{*}$ \\
\hline Volume (mm $\left.{ }^{3}\right)$ & 1.729 & 0.116 & 4.12 & $0.003 * *$ & 10.90 & $0.000^{* *}$ & 16.69 & $0.000^{* *}$ \\
\hline Bone Density (HU) & 7.55 & $0.000^{* *}$ & 11.53 & $0.000^{* *}$ & 3.27 & $0.01 *$ & 9.17 & $0.000^{* *}$ \\
\hline
\end{tabular}

*Statistically significant: $(P<0.05)$

**High statistically significant: $(P<0.01)$.

TABLE (3) Amount of changes occur in the measurements from baseline to 6 months for both groups:

\begin{tabular}{|c|c|c|c|c|}
\hline Parameters & $\begin{array}{c}\text { Group I } \\
\text { Mean } \pm \text { SD }\end{array}$ & $\begin{array}{c}\text { Group II } \\
\text { Mean } \pm \text { SD }\end{array}$ & t-value & P-value \\
\hline Bone Height & $-0.75 \pm 0.47$ & $-1.96 \pm 0.84$ & 5.021 & $0.000^{* *}$ \\
\hline Mesio-distal & $-0.46 \pm 0.31$ & $-0.61 \pm 0.29$ & 11.067 & 0.431 \\
\hline Bucco-lingual & $-0.64 \pm 0.51$ & $-0.87 \pm 0.47$ & 21.816 & 0.062 \\
\hline Volume (\% change) & $19.11 \pm 2.07$ & $36.05 \pm 3.52$ & 6.054 & $0.000^{* *}$ \\
\hline Bone Density (HU) & $+262.60 \pm 67.82$ & $+149.51 \pm 12.77$ & 5.046 & $0.000^{* *}$ \\
\hline
\end{tabular}

*Statistically significant: $(P<0.05)$

percent of volume change (table 3). While, means values of change in mesiodistal and buccolingual measurements showed no statistically significant difference between both groups. Where, means values of change were higher in group II than group I regarding to bone height and percent of change in volume scores. In opposite side, the amount of change in bone density was higher in group I than group II.

\section{Histological evaluation}

All biopsies showed newly formed bone, residual graft material, and well vascularized non-inflamed connective tissue.No necrosis or foreign body reactions were detected. Residual graft granules were in contact with active osteoblasts forming
**High statistically significant: $(P<0.01)$.

osteoid and new woven bone, demonstrating persistent osteogenesis.

In group I, specimens filled with regular areas of bone calcification of compact type with wellformed Haverssian system composed of concentric bone lamellae enclosing central Haverssian canals. There was a very small area of loose fibrous tissue composed of fine collagen fibers, fibroblast cells and blood vessels containing red blood cells. All specimens presented showed complete maturation of bone with little amount of residual graft in some cases (Fig. 4A).

While in group II, specimens presented at periphery a thick layer of newly formed compact bone characterized by Haverssian system composed 


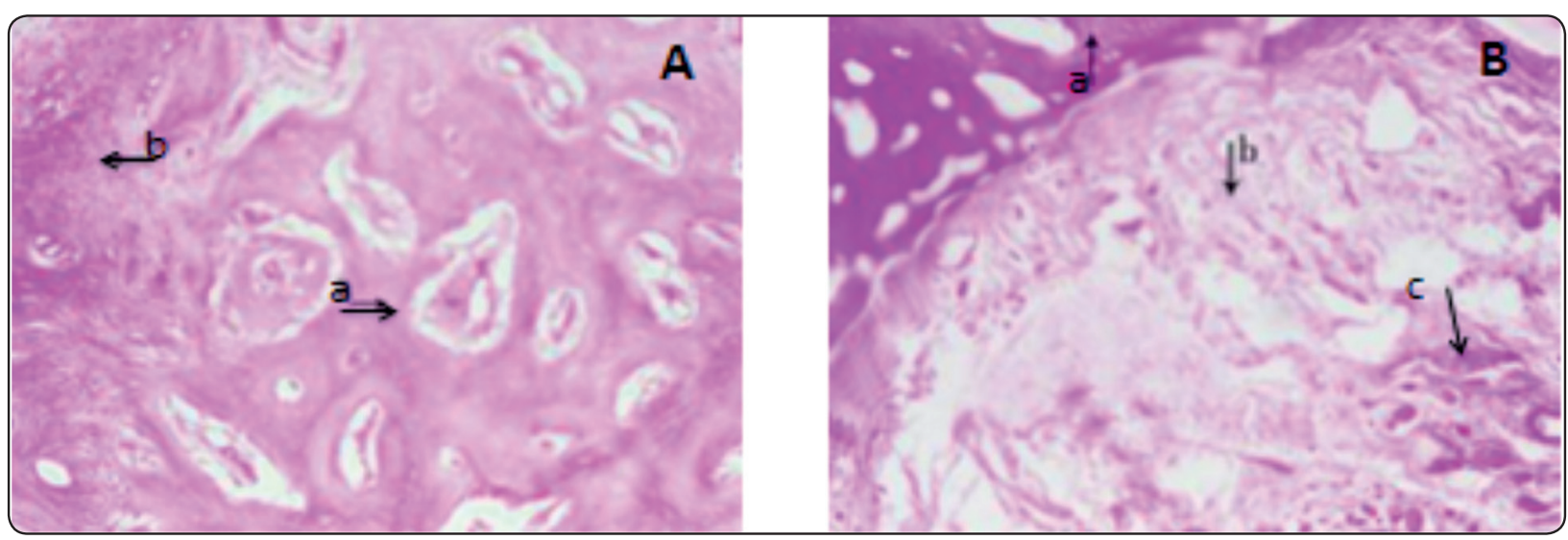

Fig. (4) (A)Microscopic photographic for group I at 6month , arrow (a) pointed to mature spongy bone, arrow (b) pointed to thin area of loose fibrous connective tissue areas.(B)Microscopic photographic for group II at 6month , arrow (a) pointed to thick layer of newly formed compact bone trabeculae with Haverssian canal, arrow (b) pointed to fine fibrous connective tissue and followed by dense fibrous connective tissue at the center, arrow (c) pointed to residual bone graft(100 X).

of concentric layers of bone lamellae encircling centrally placed Haverssian canals. The rest of the specimen was filled by fibrous connective tissue composed of collagen fibers and fibroblast cells. At the next layer to the newly formed bone, the collagen fibers were less dense, mixed with remnants of residual bone graft in all specimens. Accordingly, complete bone maturation occurred later than in group I than group II (Fig.4B).

\section{DISCUSSION}

Post extraction resorption of the alveolar ridge is a progressive and irreversible process following a removal of teeth. Where tooth extraction is a traumatic surgical procedure initiates a complex cascade of biochemical and histological events that inevitably lead to a reduction of alveolar bone and soft tissue ${ }^{(21)}$. These changes at the extraction site may be due to the loss of periodontal ligament fibers, bundle bone, and loss of blood supply. These morphologic changes pose significant challenges in restorative treatment, as soft tissue recession and buccal plate resorption define the anatomical profile of the socket and may narrow the viable treatment options. ${ }^{(22)}$ Accordingly, reconstructions of resorbed alveolar ridges and alveolar ridge preservation have been a goals and challenges of clinicians to create an anticipated foundation for implant placement to optimize the outcomes ${ }^{(4-7)}$.

Regarding socket preservation, different grafting materials have been used including; autogenous bone graft, allograft, xenograft and alloplasts ${ }^{(4)}$.The use of autogenous bone has always been the gold standard, but at times, autogenous bone harvesting is not feasible, where now the alternatives are allografts, xenograft or alloplastic materials used alone or in mixture with platelet enriched growth factors with GTR or no ${ }^{(7-9)}$.

Current study used a mixture of HyA with Osteon II collagen in group I and sticky bone in group II to fill extracted socket, and to decrease bone resorption after tooth extraction throughto benefit from regenerative proprieties of HyA and autologous concentrated growth factors.

Our study used Osteon II collagen which is alloplastic material containing 70\% HA and 30\% $\beta$ - TCP which are quite close to major mineral components of the human bone ${ }^{(10,11)}$. Moreover, bovine type I collagen was added to Osteon II material to increase its osteoconductivity. Where, the collagen is absorbed slowly over several weeks after helping the initial shaping ${ }^{(12)}$.This matched with Bae JH et al. ${ }^{(23)}$ who found that the advantage 
of combining an insoluble HA with a resorbable $\beta$-TCP is the slow-resorbing HA will maintain the volume, while faster-resorbing $\beta$-TCP will promote bone regeneration.

In the present study, Hyaluronic acid was used in mixture with Osteon II collagen in group I to benefit from regenerative proprieties of HyA .This was in the same side of Shammal et $\mathrm{al}^{(18)}$ and Aguado et $\mathrm{al}^{(19)}$ who stated that HyA has osteoconductive activity; it accelerates the bone regeneration by means of chemo taxis, proliferation and successive differentiation of mesenchyme cells.

In the same context, our study used autologous concentrated growth factors in mixture with Osteon II collagen (sticky bone) in group II.This was in accordance with Lobo et al study ${ }^{(24)}$ which reported the presence of porosity and bioactive surface in the biphasic calcium phosphate when used in combination with PRF facilitating cell attachment, proliferation and differentiation which in turn provides more biocompatible, osteoconductive and osteoinductive combination leading to more new bone formation than when BCP used alone. This is due to the formation of stable scaffold allowing for vascular in growth inside the scaffold.

Accordingly, aim of the current study was to compare clinically and radiographically the potentiality of both a mixture of HyA with Osteon II collagen and a mixture of autologous fibrin glue with Osteon II collagen (sticky bone graft) in preservation of the alveolar ridge and reducing the bone dimensional changes following tooth extraction in sites planned for delayed implant placement.

This study was conducted on 30 fresh extracted sockets at mandibular first molar. Where, bone resorption is most occurred at posterior mandibular teeth than maxillary teeth. It was matched with $\mathrm{Fu} \mathrm{J}$ et al ${ }^{(25)}$ who reported that bone reduction in a width of approximately $25 \%$ after 1 year of tooth extraction in the mandible showed a bone loss rate 4 times higher than the maxilla.
Clinical results of our study presented that no significant difference between both groups at all intervals of the study. Where, all patients showed excellent soft tissue healing and fully keratinized mucosa without any signs of inflammation, infection or dehiscence. These results can be explained byusage of collagen membrane to cover surgical area under soft tissue flaps in all groups which prevented the apical migration of epithelium and supported new connective tissue attachment and tissue regeneration that demonstrated by Dimitriou et al (26) study. Another explanation is regenerative proprieties of PRF such as induce endothelial cell proliferation and improved wound angiogenesis and ability of Hy A to improve microcirculatory perfusion at the site of tissue repair in the wound area, and accelerated wound closure. This is in the same side with Roy et al. ${ }^{(27)}$, and Bansal et $\mathrm{al}^{(28)}$.

Regarding postoperative infection ,no evidence of post-operative infection or dehiscence was noticed in this study. This may be due to the application of sterile surgical procedure, the useof antibiotic during postoperative and infection prevention propriety of PRF and Hy A. Where, PRF has high content of leukocytes which might have a role in the regulation of inflammation and prevention of infection. This is in accordance with Dohan Ehrenfest et al report ${ }^{(14)}$. Also, HyA has bacteriostatic and anti- inflammatory actions. This is in the same side with Pirnazar et al ${ }^{(29)}$ study conclusion that stated at clinical application of HyA gels may reduce the bacterial contamination of surgical wound site, thereby, lessening the risk of post-surgical infection and promoting more predictable bone generation .Also, Kim et al ${ }^{(30)}$ found out that HyA, because of its osteoinductive, bacteriostatic, and anti- inflammatory properties, may improve bone formation and accelerate wound healing in infected sockets.

Radiographic measurements of current study presented that nostatistically significant difference between both groups regarding mesiodistal and 
buccolingual measurements at all intervals. This may be explained by both groups covered by the same GTR membrane and both HyA and autologous concentrated growth factors have regenerative proprieties which retard contraction of socket width. This is consistent with Nevins et al. ${ }^{(31)}$ study which emphasized on the importance of bone grafting following tooth extraction in preserving buccal plate integrity and in consequence, alveolar ridge dimensions for ideal implant treatment. Also, these results are consistent with an article published by Araujo et al. ${ }^{(32)}$ who demonstrated that the placement of a biomaterial in an extraction socket will enhance bone modeling and compensate the marginal ridge contraction.

On the other side, measurements of bone height and volume of grafted socket decreased in sticky bone group more than group of mixture HyA with osteon II collagen with statistically significant difference between both groups at 3 month interval and highly statistically significant difference at 6 month intervals. This in agreement with Nevins et al. ${ }^{(33)}$ and park et al. ${ }^{(34)}$ who reported that although Sticky bone can be easily modeled and retains its shape during preparation and placement, it does not maintain its original dimensions after placement into bone defects and provides no structural stability.

Regarding bone density scores increased in both groups with superiority for group I than group II. Therefore, there was highly statistically significant difference between both groups at 3, 6 month intervals ,although both group did not show any statistically significant difference at baseline. This was in the same line with our results of histological evaluation for bone specimens at 6 months. That showed earlier bone maturation with complete bone formation in group I than group II.

This is in agreement with Ozemir et al. ${ }^{(20)}$ who demonstrated that the use of PRF can increase density of the newly formed bone because of the presence of concentrated growth factor in the PRF. While, HyA has several mechanisms to bone formation ,and increased bone density. It induces bone formation similar to osteogenic substrates such as calcitonin and bone morphogenic protein. In addition, it binds proteins crucial for wound healing, such as fibrinogen, fibrin, and collage. This is in the same line with Aslan etal. ${ }^{(35)}$ who demonstrated that the Osteon II collagen with hyaluronic acid groups has superiority bone healing histologically. Where, the newly formed bone consisted of trabeculae extending towards the core of the defect with obvious complete osseointegration with the native bone.The new bone trabeculae were large and showed narrow marrow spaces. This can be explained by when in close contact with bone; HyA participates in bone morphogenesis and the early osteogenesis events modulating the effects of several cytokines and growth factors.

On contrary to our results, Aguado et al. ${ }^{(36)}$ investigated the use of hyaluronic acid ( $\mathrm{HyA}$ ) as aqueous binder of the BCP bone graft granules. They found out that the amount of formed bone was not significantly higher than with BCP granules alone. HyA was rapidly eluted from the grafted zone but allowed deposition of more granules. Explanation of different our results, because we used osteon II combined with collagen which increase osteoconductivity of bone graft.

\section{CONCLUSION}

From the results of the study, it can be concluded that a mixture of osteon II collagen with HyA has a highly regenerative effect compared with sticky bone graft that leads to decrease bone resorption leading to preserve on 3- D volume with increased bone density of alveolar ridge after tooth extraction.

\section{Conflicts of interest}

There are no conflicts of interest. 


\section{REFRANCES}

1. Hoffmann O, Bartee BK, Beaumont C, Kasaj A, Deli G, Zafiropoulos G-G.Alveolar bone preservation in extraction sockets using non-resorbable dPTFE membranes: a retrospective non-randomized study. J.Periodontol. 2008; 79(8):1355-69.

2. Schropp L, Wenzel A, Kostopoulos L, Karring T.Bone healing and soft tissue contour changes following singletooth extraction: a clinical and radiographic 12-month prospective study. Int. J. Periodontics \& Restorative Dentistry. 2003;23(4):313-23.

3. Chappuis, V., Engel, O., Reyes, M., Shahim, K., Nolte, L. P., \& Buser, D.Ridge alterations post-extraction in the esthetic zone: A3D analysis with CBCT. Journal of Dental Research 2013, 92: 195-201.

4. Iasella JM, Greenwell H, Miller RL, Driskio C, Bohra AA, Scheetz P.Ridge preservation with freeze-dried bone allograft and a collagen membrane compared to extraction alone for implant site development: a clinical and histological study in humans.J.Periodontol.2003,74:990-9.

5. Pagni G., Pellegrini G,Giannobile W.,Asperini G."Post extraction alveolar ridge preservation: biological basis and treatments". International Journal of Dentistry 2012(1):151030.

6. Weng D., Stock V., Schliephake H.“Are socket and ridge preservation techniques at the day of tooth extraction efficient inmaintaining the tissues of thealveolar ridge?". European Journal of Oral Implantology 2011; 4;5:5-10.

7. Ten Heggeler JMAG.,Slot DE, Van der Weijden. "Effect of socket preservation therapies following tooth extraction in non-molar regions in humans: a systematic review". Clinical Oral Implants Research 2011;22.8: 779-788

8. Artzi Z., Tal H,Dayan D.“Porous bovine bone mineral in healing of human extraction sockets. Part 1: Histomorphometric evaluations at 9 months". Journal of Periodontology 71.6 (2000): 1015-239.

9. Reddy S, Prasad MGS, Prasad S, Bhowmick N, Sravya L, Amir A, Krishnanad P : Extraction socket preservation using $\beta$ tricalcium phosphate bone graft plug and platelet rich fibrin membrane 2014; 1(1): 39-43

10. Kim YK.,Yun PY., Lim SC., Kim SG .\& Lee HJ,Ong JL. Clinical evaluation of Osteon as anew alloplastic material in sinus bone grafting and its effect on bone healing. J Biomed. Mat. Res. B Appl Biometer 2008;86:270-7.
11. Keating J.F \& McQueen M.M. Substitutes for autologous bone graft in orthopedic trauma. J Bone Joint Surg Br.2001;83(1):3-8 .

12. Lee EU, Kim DJ, Lim HC, Lee JS, Jung UW, Choi SH. Comparative evaluation of biphasic calcium phosphate and biphasic calcium phosphate collagen composite on osteoconductive potency in rabbit calvarial defect. Biomaterials Research. 2015; 19: 1-7

13. Plachokova AS., et al. "Effect of platelet-rich plasma on bone regeneration in dentistry: a systematic review". Clinical Oral Implants Research 2008;19(6) : 539-45.

14. Dohan Ehrenfest DM, Bielecki T, Jimbo R, Barbe' G, Del Corso M, Inchingolo F, Sammartino G. Do the fibrin architecture and leukocyte content influence the growth factor release of platelet concentrates? an evidence based answer comparing a pure platelet-rich plasma (P-PRP) gel and a leukocyte- and platelet-rich fibrin (L-PRF). Curr Pharm Biotechnol 2012; 13:1145-1152

15. Rodella LF.,Favero G,Boninsegna R, et al.“Growth factors, CD34 positive cells, and fibrin network analysis in concentrated growth factors fraction".et al. "Growth factors, CD34 positive cells, and fibrin network analysis in concentrated growth factors fraction". Microscopy Research and Technique 2011;74(8) : 772-7.

16. EL Moheb Mohamed. "The Use of Growth Factors Fibrin Network to Enhance Architecture, Mechanical and Biological Aspect of the Graft Particles". International Journal of Preventive \& Clinical Dental Research 2014; 1(.2): 41-44.

17. Sohn S, Huang B, Kim J, Park E, Park C. Utilization of Autologous Concentrated Growth Factors (CGF) Enriched Bone Graft Matrix (Sticky Bone) and CGF-Enriched Fibrin Membrane in Implant Dentistry. JIACD,2015;7(10);11-29.

18. Shammal MM, Ayad SS, El-dibany RM, Nagui DA. Evaluation of the effect of hyaluronic acid mixed with biphasic calcium phosphate on bone healing around dental implants (experimental study). ADJ 2017;.42:104-11.

19. Aguado E, Florence P, Christine G, Eric G, Daniel C. $\beta$ TCP granules mixed with reticulated hyaluronic acid induces an increase in bone apposition. Biomed Mater. 2013; 9(1): 015001.

20. Intini G. The use of platelet-rich plasma in bone reconstruction therapy. Biomaterials. 2009;30:4956-66

21. Caplanis N, Lozada JL, Kan JY. Extraction defect assessment, classification, and management.J Calif Dent Assoc. 2005;33(11):853-63. 
22. Elian N, Cho SC, Froum S, Smith RB, Tarnow DP, "A simplified socket classification and repair technique," Practical Procedures \& Aesthetic Dentistry, 2007; 19 (2): 99-104.

23. Bae JH, Kim YK, Kim SG, Yun PY, Kim JS. Sinus bone graft using new alloplastic bone graft material (Osteon)-II: clinical evaluation. Oral Surg Oral Med Oral Radiol Endod 2010; 109:14-20

24. Lobo SE, Wykrota FH, Oliveira AC, Kerkis I, Mahecha GB, Alves HJ. Quantification of bone mass gain in response to the application of biphasic bioceramics and platelet concentrate in critical-size bone defects. J Mater Sci Mater Med. 2009;20:1137-47

25. Fu JH,Wang HL. Horizontal bone augmentation; the decision tree. Int J Periodontics Restorative Dent 2011; 31:429-436.

26. Dimitriou R, Mataliotakis G, Maria G, Giannoudis C.The role of barrier membranes for guided bone regeneration and restoration of large bone defects: current experimental and clinicalevidence. BMC Medicine 2012;10:81

27. Roy S, Driggs J, Ehgharably H, Biswas S, Findley M, Khanna S, et al. Platelet rich fibrin matrix improves wound angiogenesis via inducing endothelial cell proliferation. Wound Repair Regen. 2011; 19:753-66.

28. Bansal J., Kedige SD.\& Anand S. Hyaluronic acid: a promising mediator for periodontal regeneration. Indian $\mathrm{J}$ Dent Res. 2010; 21(4):575-8.
29. Pirnazar P., Wolinsky L., Nachnani S., Haake S., Pilloni A.\& Bernard GW. Bacteriostatic effects of hyaluronic acid. J periodontal. 1999; 70(4):370-4

30. Kim JJ, Song HY, Ben Amara H, Kyung-Rim K, Koo KT. Hyaluronic Acid Improves Bone Formation in Extraction Sockets with Chronic Pathology: A Pilot Study in Dogs. J Periodontol. 2016; 87(7): 790-5

31. Nevins M, Camelo M, Paoli S, et al. A study of the fate of the buccal wall of extraction sockets of teeth with prominent roots. Int J Periodontics Restorative Dent 2006; 26(1):19-29.

32. Araújo M, Linder E, Wennström J, Lindhe J. The influence of Bio-Oss Collagen on healing of an extraction socket: an experimental study in the dog. Int J Periodontics Restorative Dent. 2008;28(2):123-35.

33. Nevins M, Mellonig JT. Enhancement of the damaged edentulous ridge to receive dental implants: A combination of allograft and the GORE-TEX membrane. Int J Periodontics Restorative Dent 1992; 12:96-11.

34. Park HC, Kim SG, Oh JS, et al. Early bone formation at a femur defect using CGF and PRF grafts in adult dugs: A comparative study. Implant Dent 2016; 25: 387-393.

35. Aslan M.,Simsek G. \& Dayi E. The effect of hyaluronic acid-supplemented bone graft in bone healing: experimental study in rabbits. J Biomater Appl. 2006; 20(3):209-20.

36. Aguado E, Florence P, Christine G, Eric G, Daniel C. $\beta$ TCP granules mixed with reticulated hyaluronic acid induces an increase in bone apposition. Biomed Mater. 2013; 9(1): 015001. 